\title{
Correction to: Novel loci and mapuche genetic ancestry are associated with pubertal growth traits in Chilean boys
}

\author{
Lucas Vicuña ${ }^{1,2} \cdot$ Tomás Norambuena $^{1,2} \cdot$ José Patricio Miranda ${ }^{1} \cdot$ Ana Pereira $^{3} \cdot$ Veronica Mericq $^{4} \cdot$ Linda Ongaro $^{5}$. \\ Francesco Montinaro ${ }^{5}$. José L. Santos ${ }^{6}$. Susana Eyheramendy ${ }^{1,2}$ (1)
}

Published online: 3 August 2021

๑) Springer-Verlag GmbH Germany, part of Springer Nature 2021

\section{Correction to: Human Genetics}

https://doi.org/10.1007/s00439-021-02290-3

Several typos were introduced in the original article and they have been corrected.

The original article has been revised.
Publisher's Note Springer Nature remains neutral with regard to jurisdictional claims in published maps and institutional affiliations.

The original article can be found online at https://doi.org/10.1007/ s00439-021-02290-3.

Susana Eyheramendy

susana.eyheramendy@uai.cl

1 Faculty of Engineering and Sciences, Universidad Adolfo Ibáñez, Peñalolén, Santiago, Chile

2 Instituto Milenio de Investigación Sobre los Fundamentos de los Datos (IMFD), Santiago, Chile

3 Institute of Nutrition and Food Technology, University of Chile, Santiago, Chile

4 Institute of Maternal and Child Research, Faculty of Medicine, University of Chile, Santiago, Chile

5 Estonian Biocentre, Institute of Genomics, University of Tartu, Riia 23b, 51010 Tartu, Estonia

6 Department of Nutrition, Diabetes and Metabolism, School of Medicine, Pontificia Universidad Católica de Chile, Santiago, Chile 